\title{
Gene Section
}

\section{Review}

\section{MIR135A1 (microRNA 135a-1)}

\author{
Alfons Navarro, Marina Díaz-Beyá, Mariano Monzó \\ Molecular Oncology and Embryology Laboratory, Human Anatomy Unit, School of Medicine, \\ University of Barcelona, Barcelona, Spain (AN, MM), Hematology Department, Hospital Clinic, \\ IDIBAPS, Barcelona, Spain (MDB)
}

Published in Atlas Database: February 2014

Online updated version : http://AtlasGeneticsOncology.org/Genes/MIR135A1ID50328ch3p21.html DOI: $10.4267 / 2042 / 54132$

This work is licensed under a Creative Commons Attribution-Noncommercial-No Derivative Works 2.0 France Licence. (c) 2014 Atlas of Genetics and Cytogenetics in Oncology and Haematology

\section{Abstract}

Review on MIR135A1, with data on DNA/RNA and where the gene is implicated.

\section{Identity}

Other names: MIRN135-1, MIRN135A1

HGNC (Hugo): MIR135A1

Location: $3 \mathrm{p} 21.1$

Local order: Genes flanking MIR135A1 oriented from centromere to telomere on 3p21.1:

- PHF7: PHD finger protein 7, 3p21.1

- BAP1: BRCA1 associated protein-1 (ubiquitin carboxy-terminal hydrolase), 3p21.31-p21.2

- DNAH1: dynein, axonemal, heavy chain 1, $3 \mathrm{p} 21.1$

- MIR135A1

- GLYCTK-AS1: GLYCTK Antisense RNA 1 (Non-protein coding), 3p21.1
- GLYCTK: glycerate kinase, 3p21.1

- TCONS_00006853; lnc-GLYCTK-1, 3p21.1

- WDR82: WD repeat domain 82, 3p21.2

- MIRLET7G: microRNA let-7g, 3p21.1.

\section{DNA/RNA}

\section{Description}

The gene is located in the intron 1 of GLYCTKAS1/RP11 gene (sense) and in the exon 4 of GLYCTK (antisense). The precursor length is 90 nt.

\section{Transcription}

The transcription of miR-135a is regulated by FOXM1 in hepatocellular carcinoma (Liu et al., 2012). BMP2 inhibits miR-135a expression during osteoblast differentiation (Li et al., 2008).

\section{Pseudogene}

No reported pseudogenes.

miR-135a-5p
a $\mathrm{g}$
u u
uu
uucua
g ccucgcugu c cuauggcuu aurccuauguga c

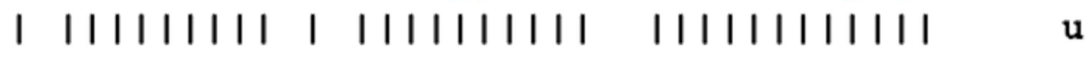
c ggggcggca g ggugccgagg uagggauauacu $\mathrm{g}$
a a
c C
$-u$
cacuc
miR-135a-3p

Stem-loop structure of hsa-mir-135a-1. 


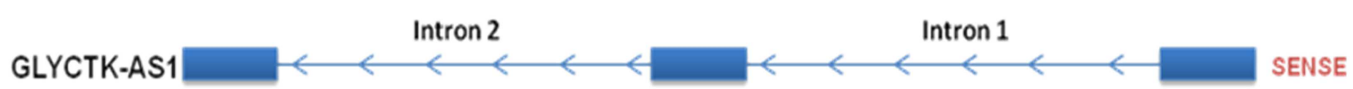

MIR135A1

\section{Protein}

\section{Note}

MicroRNAs are not translated into amino acids.

\section{Mutations}

\section{Note}

Deletions of miR-135a-1 gene have been described in medulloblastomas, where $16 / 48$ (33\%) of medulloblastoma patients had a deletion of miR135a-1 gene (Lv et al., 2012).

\section{Implicated in}

\section{Cancer}

\section{Colorectal cancer (CRC)}

\section{Note}

Interestingly, treating $\mathrm{CRC}$ cell lines with mistletoe lecitin-I, degrades precursor of some microRNAs, including pre-mir-135a, thus dowregulating miR135 and upregulating APC and increasing betacatenin phosphorylation ( $\mathrm{Li}$ et al., 2011).

\section{Prognosis}

A prognostic miRNA signature composed of miR135a, miR-21, miR-335, miR-206 and let-7a was useful to detect the presence of metastasis (Vickers et al., 2012).

\footnotetext{
Oncogenesis

Oncogene.

miRNA expression: Overexpression among colorectal adenome and carcinome in comparison with normal tissue. miR-135 family (miR-135a and miR-135b) overexpression during CRC progression (in patients) (Nagel et al., 2008). Consistently, a study comparing patient samples, healthy controls and cell lines showed overexpression in CRC samples (Zhou et al., 2012). Another study also showed overexpression associated with progression and metastasis (Vickers et al., 2012).

Targets: Adenomatous polyposis coli (APC) (Nagel et al., 2008). Metastasis suppressor 1 (MTSS1) (Zhou et al., 2012).
}

Function: miR-135a and miR-135b inhibits APC translation (independently of mutational status of APC) activating downstream Wnt pathway activity and induce beta-catenin signaling (Nagel et al., 2008). In CRC cell lines, miR-135a overexpression increased proliferation and promoted mobility and invasion in part by targeting MTSS1 (Zhou et al., 2012).

\section{Gastric cancer}

\section{Oncogenesis}

Tumor suppressor (Wu H et al., 2012).

miRNA expression: Downregulation in gastric cancer patient samples in comparison with adjacent normal tissue.

Targets: JAK2 (Janus kinase 2)

Function: miR-135a overexpression produces downregulation of JAK2 levels reducing cell proliferation and colony formation. It also reduces p-STAT3 (phospho signal transducer and activator of transcription 3) activation and cyclin D1 and Bcl-x (BCL2-like1).

\section{Hepatocellular carcinoma (HCC)}

Prognosis

In a cohort of 50 patients, overexpression of miR135a identified a group of patients with worse OS end DFS among patients with PVTT.

\section{Oncogenesis}

Oncogene (Liu et al., 2012).

miRNA expression: Overexpression of miR-135a in samples from HCC with portal vein tumor thrombus (PVTT) - that is considered a special type of HCC metastasis - compared with parenchyma tumor nodes.

Targets: MTSS

Function: miR-135a promotes invasion and metastasis in vitro and in mouse models of HCC. Reducing miR-135a leads to reduced PVTT. The transcription of miR-135a is regulated by FOXM1.

\section{Breast cancer}

Oncogenesis

Oncogene (Chen et al., 2012). 
miRNA expression: Overexpression in metastasic breast tumors in comparison with benign tumor patient samples. Upregulation in the highly invasive breast cancer cell line BT 549 in comparison with other breast cancer cell lines.

Targets: HOXA10 (homeobox A10).

Function: miR-135a promotes the migration and invasion of breast cancer cells at least in part through HOXA10.

\section{Malignant glioma}

\section{Oncogenesis}

Tumor suppressor (Wu S et al., 2012).

miRNA expression: Downregulated in glioma in comparison with normal glia. miRNA-135a correlated negatively with the pathological grading of human glioma tissue samples.

Targets: STAT6 (signal transducer and activator of transcription 6), SMAD5 (SMAD family member 5), BMPR2 (bone morphogenetic protein receptor, type II).

Function: miR-135a selectively induces mitochondria-dependent apoptosis of malignant glioma by targeting various genes (STAT6, SMAD5, BMPR2). Interestingly it doesn't affect normal glia cells.

\section{Lung cancer}

Oncogenesis

Tumor suppressor (Cheng et al., 2013; Zhou et al., 2013).

miRNA expression: $\mathrm{miR}-135 \mathrm{a} / \mathrm{b}$ downregulated in the cisplatin-resistant cell line A549R compared with the cisplatin-sensitive A549 cell line (Zhou, Qiu et al. 2013).

Targets: MCL1 (myeloid cell leukemia sequence 1) (Zhou et al., 2013), CD133 (Cheng et al., 2013).

Function: Overexpression of $\mathrm{miR}-135 \mathrm{a} / \mathrm{b}$ reduced MCL1 and sensitized cell lines to cisplatin by modulation of apoptosis (Zhou et al., 2013). miR$135 \mathrm{a} / \mathrm{b}$ suppressed CD133 only in CD133 with binding polymorphism rs2240688 CC or CA but not in genotype AA (Cheng et al., 2013).

\section{Classic Hodgkin lymphoma (cHL)}

\section{Prognosis}

In a cohort of $89 \mathrm{cHL}$ patients, low miR-135a was associated with a higher risk of relapse and worse disease free survival.

\section{Oncogenesis}

Tumor suppressor (Navarro et al., 2008; Navarro et al., 2009).

miRNA expression: Downregulated miR-135a in cHL patient lymph nodes in comparison with reactive non-tumor lymph nodes used as control.

Targets: JAK2.

Function: Overexpression of miR-135a increases apoptosis and decreases cellular growth in HL cell lines through regulation of JAK/STAT pathway and activation $\mathrm{BcL}-\mathrm{xL}$ expression.

\section{Acute myeloid leukemia (AML)}

\section{Prognosis}

In a cohort of 85 intermediate risk AML (IR-AML) patients (later extended to 238 IR-AML patients), low expression of miR-135a identified a group of patients with a higher risk of relapse - both in the entire cohort and also within the unfavourable molecular subgroup (FLT3-ITD or wild-type NPM and CEBPA) (Díaz-Beyá et al., 2014).

Oncogenesis

Tumor suppressor.

\section{Renal cell carcinoma}

\section{Oncogenesis}

Tumor suppressor (Hidaka et al., 2012).

miRNA expression: Lower expression of miR135a observed in 10 cancer tissue samples compared to 5 adjacent non-cancer tissue samples.

Function: Effect on cell proliferation, where the miR-135a overexpression reduces cell viavility.

\section{Cervival cancer cell}

Oncogenesis

Oncogene (Leung et al., 2014).

miRNA expression: miR-135a is overexpressed in cervical squamous cell carcinoma in comparison with cervical intraepithelial neoplasia (precancerous lesions).

Targets: SIAH1 (in cervical cancer cells and cervical epithelial cells).

Function: Overexpression of miR-135a induced increased colony formation, anchorage-independent growth, and proliferation, cell-invasion and migration in cervical cancer cell lines.

The inhibition of miR-135a on SIAH1 led to upregulation of beta-catenin activity, indicating that miR-135a induces transformation and enhances tumor growth.

The authors analyzed the miR-135a-induced malignant transformation activity in cell lines with or without human papiloma virus (HPV) proteins (E6 and E7) and concluded that these proteins are necessary for miR-135a oncogenic activity.

Also in xenografts, miR-135a improved the growth of cancer cells and the tumorigenic activity of HPV cells.

\section{Various tumor cell lines (HeLa cervical carcinoma, SW480 colon cancer, A375 melanoma, PANC-1 pancreatic tumor, and 293 epithelial kidney cells)}

Note

FAK is overexpressed in many cancers. 
Oncogenesis

Tumor suppressor (Golubovskaya et al., 2014).

Targets: FAK (focal adhesion kinase).

Function: miR-135a overexpression decreased FAK mRNA and protein levels, decreased cell invasion and increased sensitivity to doxorubicin, 5-fluorouacil and FAK inhibitor Y15.

\section{Various tumor cell lines}

Oncogenesis

Oncogene (Holleman et al., 2011).

miRNA expression: miR-135a levels were significantly upregulated in paclitaxel-resistant ovarian, lung, uterine, breast and prostate tumor cells lines derived from A549, PC-14, MCF-7, PC3, SKOV-3 and MES-SA.

Targets: APC.

Function: miR-135a upregulation in vitro and in vivo is associated with paclitaxel resistance. AntimiR-135a treatment in paclitaxel-resistant lung cancer xenografts restored sensitivity to paclitaxel, in part through the direct inhibition of APC expression.

\section{Metabolism \\ Diabetes}

\section{Note}

miRNA expression: Overexpression in diabetic human and mouse skeletal muscle.

Targets: IRS2 (insulin receptor substrate 2).

Function: miR-135a inhibits IRS2, thus reducing glucose uptake into the cell. miR-135a overexpression attenuates insulin signaling and glucose uptake in skeletal muscle. In vivo, silencing miR-135a decreases hyperglicemia (Agarwal et al., 2013).

\section{Essential hypertension, renin- angiotensin-aldosteron system}

Note

Targets: NR3C2 (mineral corticoid receptor).

Function: In Hela cells, overexpression of miR$135 \mathrm{a}$ and miR-124 downregulates NR3C2 protein, indicating a role in the regulation of blood pressure (Sõber et al., 2010).

\section{Corticoid dependent stress response}

Note

Targets: NR3C2 (mineral corticoid receptor, other alias MR)

Function: In a mouse model, downregulation of miR-135a and miR-124 in amygdale after two hours of stress stimulus.

Stress reaction by activation of corticosteroid signaling through NR3C2R. miR-135a and miR124 are thus important components of the stress signaling response in the brain (Mannironi et al., 2013).

\section{Development, congenital disease and others}

\section{Cryptorchid testis}

Note

miRNA expression: In rat models, low expression of miR-135a in undescended testis in comparison with that in contralateral normal testis. Higher miR135 a expression in the testes than in other organs. miR-135a is detected in spermatogonial stem cells.

Targets: FoxO1 (forehead box protein O1).

Functions: miR-135a contributes to spermatogonial stem cell maintenance through modulation of FoxO1 (Moritoki et al., 2014).

\section{Endometriosis}

\section{Note}

miRNA expression: Overexpressed in endometriosis in comparison with normal endometrial tissue (50 controls and 32 women with endometriosis).

Targets: HOXA10 (homeobox A10).

Function: miR135a expression in controls was increased during the proliferative phase, decreased at the time of ovulation, and increased during the luteal phase (Petracco et al., 2011).

\section{Osteogenesis}

Note

miRNA expression: Very low levels in differentiated osteoblast, downregulated during BMP2-mediated osteogenic differentiation.

Targets: SMAD5.

Function: miR-135a suppresses osteogenesis and inhibits differentiation of osteoprogenitors and the osteogenic phenotype in pluripotent cells by attenuating SMAD5. BMP2 inhibits miR-135a expression and permits osteoblast differentiation (Li et al., 2008).

\section{Muscle differentiation (myogenesis) and Duchenne muscular dystrophy (DMD)}

Note

miRNA expression: miR-135a is upregulated during myogenic differentiation. Overexpression of miR-135a is observed when the myoblasts are differentiated in human samples, cell lines and mouse model (Greco et al., 2009). miR-135a is part of the DMD miRNA signature (Greco et al., 2009) and is overexpressed in Duchenne muscle (Cesana et al., 2011).

Targets: MEF2C (myocyte enhancer factor 2C) (Cesana et al., 2011).

Function: Critical in myogenesis by targeting MEF2C. miR-135a inhibits MEF2C, leading to inhibition of muscle genes. LincRNA MD1 sponges miR-135a, allowing transcription of muscle genes. 
LincRNA MD1 is reduced in Duchenne muscle cells, so miR-135a is overexpressed and MEFC2 is downregulated (Cesana et al., 2011).

\section{Preimplantation embryo development} Note

miRNA expression: Overexpressed in mouse zygote and decreased thereafter, indicating that it is a zygote-specific miRNA.

Targets: SIAH1A (E3 ubiquitin ligase seven in absentia homolog 1A).

Function: miR-135a modulates the first cell cleavage through regulation of Siah1a. When miR$135 \mathrm{a}$ is inhibited, first cell cleavage is suppressed. mir-135a regulates proteosomal degradation (Pang et al., 2011).

\section{Mouse embryonic stem cells}

\section{Note}

miRNA expression: Upregulated during mouse embryonic stem cell differentiation.

Targets: SIRT1 (sirtuin 1).

Function: Together with miR-181a, miR-181b, miR-9, miR-204 and miR-199b, miR-135a suppressed SIRT1 protein expression during mouse embryonic stem cell differentiation (Saunders et al., 2010).

\section{Bovine blastocyst development}

\section{Note}

miRNA expression: miR-135a is part of a downregulated miRNA signature in more mature stage (Goossens et al., 2013).

\section{Megakaryocytopoiesis}

\section{Note}

miRNA expression: A comparison between differentiated megakaryocytes with AML megakaryocytic cell lines found miR-135a higher in AML samples (Garzon et al., 2006).

\section{Hypoxia}

\section{Note}

miRNA expression: Downregulation of miR-135a (and miR199a-5p) in response to hypoxia.

Targets: FLAP (5-lipoxygenase activating protein) (Gonsalves and Kalra, 2010).

\section{References}

Garzon R, Pichiorri $F$, Palumbo $T$, luliano R, Cimmino A, Aqeilan R, Volinia S, Bhatt D, Alder H, Marcucci G, Calin GA, Liu CG, Bloomfield CD, Andreeff M, Croce CM. MicroRNA fingerprints during human megakaryocytopoiesis. Proc Natl Acad Sci U S A. 2006 Mar 28;103(13):5078-83

Li Z, Hassan MQ, Volinia S, van Wijnen AJ, Stein JL, Croce CM, Lian JB, Stein GS. A microRNA signature for a BMP2-induced osteoblast lineage commitment program. Proc Natl Acad Sci U S A. 2008 Sep 16;105(37):13906-11
Nagel R, le Sage C, Diosdado B, van der Waal M, Oude Vrielink JA, Bolijn A, Meijer GA, Agami R. Regulation of the adenomatous polyposis coli gene by the miR-135 family in colorectal cancer. Cancer Res. 2008 Jul 15;68(14):5795-802

Navarro A, Gaya A, Martinez A, Urbano-Ispizua A, Pons A, Balagué $O$, Gel B, Abrisqueta $P$, Lopez-Guillermo A, Artells R, Montserrat E, Monzo M. MicroRNA expression profiling in classic Hodgkin lymphoma. Blood. 2008 Mar 1;111(5):2825-32

Greco S, De Simone M, Colussi C, Zaccagnini G, Fasanaro $\mathrm{P}$, Pescatori M, Cardani R, Perbellini R, Isaia E, Sale P, Meola G, Capogrossi MC, Gaetano C, Martelli F. Common micro-RNA signature in skeletal muscle damage and regeneration induced by Duchenne muscular dystrophy and acute ischemia. FASEB J. 2009 Oct;23(10):3335-46

Navarro A, Diaz T, Martinez A, Gaya A, Pons A, Gel B, Codony C, Ferrer G, Martinez C, Montserrat E, Monzo M. Regulation of JAK2 by miR-135a: prognostic impact in classic Hodgkin lymphoma. Blood. 2009 Oct 1;114(14):2945-51

Gonsalves CS, Kalra VK. Hypoxia-mediated expression of 5-lipoxygenase-activating protein involves HIF-1alpha and NF-kappaB and microRNAs 135a and 199a-5p. J Immunol. 2010 Apr 1;184(7):3878-88

Saunders LR, Sharma AD, Tawney J, Nakagawa M, Okita $\mathrm{K}$, Yamanaka S, Willenbring $\mathrm{H}$, Verdin E. miRNAs regulate SIRT1 expression during mouse embryonic stem cell differentiation and in adult mouse tissues. Aging (Albany NY). 2010 Jul;2(7):415-31

Sõber S, Laan M, Annilo T. MicroRNAs miR-124 and miR$135 \mathrm{a}$ are potential regulators of the mineralocorticoid receptor gene (NR3C2) expression. Biochem Biophys Res Commun. 2010 Jan 1;391(1):727-32

Cesana M, Cacchiarelli D, Legnini I, Santini T, Sthandier O, Chinappi M, Tramontano A, Bozzoni I. A long noncoding RNA controls muscle differentiation by functioning as a competing endogenous RNA. Cell. 2011 Oct 14;147(2):358-69

Holleman A, Chung I, Olsen RR, Kwak B, Mizokami A, Saijo N, Parissenti A, Duan Z, Voest EE, Zetter BR. miR135 a contributes to paclitaxel resistance in tumor cells both in vitro and in vivo. Oncogene. 2011 Oct 27;30(43):4386-98

Li LN, Zhang HD, Zhi R, Yuan SJ. Down-regulation of some miRNAs by degrading their precursors contributes to anti-cancer effect of mistletoe lectin- $\mathrm{I} . \mathrm{Br} \mathrm{J}$ Pharmacol. 2011 Jan;162(2):349-64

Pang RT, Liu WM, Leung CO, Ye TM, Kwan PC, Lee KF, Yeung WS. miR-135A regulates preimplantation embryo development through down-regulation of $\mathrm{E} 3$ Ubiquitin Ligase Seven In Absentia Homolog $1 \mathrm{~A}$ (SIAH1A) expression. PLoS One. 2011;6(11):e27878

Petracco R, Grechukhina O, Popkhadze S, Massasa E, Zhou Y, Taylor HS. MicroRNA 135 regulates HOXA10 expression in endometriosis. J Clin Endocrinol Metab. 2011 Dec;96(12):E1925-33

Chen Y, Zhang J, Wang $\mathrm{H}$, Zhao J, Xu C, Du Y, Luo X, Zheng $F$, Liu R, Zhang H, Ma D. miRNA-135a promotes breast cancer cell migration and invasion by targeting HOXA10. BMC Cancer. 2012 Mar 23;12:111

Hidaka H, Seki N, Yoshino H, Yamasaki T, Yamada Y, 
Nohata N, Fuse M, Nakagawa M, Enokida $H$. Tumor suppressive microRNA-1285 regulates novel molecular targets: aberrant expression and functional significance in renal cell carcinoma. Oncotarget. 2012 Jan;3(1):44-57

Liu S, Guo W, Shi J, Li N, Yu X, Xue J, Fu X, Chu K, Lu C, Zhao J, Xie D, Wu M, Cheng S, Liu S. MicroRNA-135a contributes to the development of portal vein tumor thrombus by promoting metastasis in hepatocellular carcinoma. J Hepatol. 2012 Feb;56(2):389-96

Lv SQ, Kim YH, Giulio F, Shalaby T, Nobusawa S, Yang H, Zhou Z, Grotzer M, Ohgaki H. Genetic alterations in microRNAs in medulloblastomas. Brain Pathol. 2012 Mar;22(2):230-9

Vickers MM, Bar J, Gorn-Hondermann I, Yarom N, Daneshmand $\mathrm{M}$, Hanson JE, Addison CL, Asmis TR, Jonker DJ, Maroun J, Lorimer IA, Goss GD, Dimitroulakos J. Stage-dependent differential expression of microRNAs in colorectal cancer: potential role as markers of metastatic disease. Clin Exp Metastasis. 2012 Feb;29(2):123-32

Wu H, Huang M, Cao P, Wang T, Shu Y, Liu P. MiR-135a targets JAK2 and inhibits gastric cancer cell proliferation. Cancer Biol Ther. 2012 Mar;13(5):281-8

Wu S, Lin Y, Xu D, Chen J, Shu M, Zhou Y, Zhu W, Su X, Zhou Y, Qiu P, Yan G. MiR-135a functions as a selective killer of malignant glioma. Oncogene. 2012 Aug 23;31(34):3866-74

Zhou W, Li X, Liu F, Xiao Z, He M, Shen S, Liu S. MiR135 a promotes growth and invasion of colorectal cancer via metastasis suppressor 1 in vitro. Acta Biochim Biophys Sin (Shanghai). 2012 Oct;44(10):838-46

Agarwal $P$, Srivastava R, Srivastava AK, Ali S, Datta M. miR-135a targets IRS2 and regulates insulin signaling and glucose uptake in the diabetic gastrocnemius skeletal muscle. Biochim Biophys Acta. 2013 Aug;1832(8):1294303

Cheng M, Yang L, Yang R, Yang X, Deng J, Yu B, Huang $D$, Zhang S, Wang H, Qiu F, Zhou Y, Lu J. A microRNA$135 \mathrm{a} / \mathrm{b}$ binding polymorphism in CD133 confers decreased risk and favorable prognosis of lung cancer in Chinese by reducing CD133 expression. Carcinogenesis. 2013 Oct;34(10):2292-9
Goossens K, Mestdagh P, Lefever S, Van Poucke M, Van Zeveren A, Van Soom A, Vandesompele J, Peelman L. Regulatory microRNA network identification in bovine blastocyst development. Stem Cells Dev. 2013 Jul $1 ; 22(13): 1907-20$

Mannironi C, Camon J, De Vito F, Biundo A, De Stefano ME, Persiconi I, Bozzoni I, Fragapane P, Mele A, Presutti C. Acute stress alters amygdala microRNA miR-135a and miR-124 expression: inferences for corticosteroid dependent stress response. PLoS One. 2013;8(9):e73385

Zhou L, Qiu T, Xu J, Wang T, Wang J, Zhou X, Huang Z, Zhu W, Shu Y, Liu P. miR-135a/b modulate cisplatin resistance of human lung cancer cell line by targeting MCL1. Pathol Oncol Res. 2013 Oct;19(4):677-83

Díaz-Beyá M, Brunet S, Nomdedéu J, Tejero R, Díaz T, Pratcorona M, Tormo M, Ribera JM, Escoda L, Duarte R, Gallardo D, Heras I et al.. MicroRNA expression at diagnosis adds relevant prognostic information to molecular categorization in patients with intermediate-risk cytogenetic acute myeloid leukemia. Leukemia. 2014 Apr;28(4):804-12

Golubovskaya VM, Sumbler B, Ho B, Yemma M, Cance WG. MiR-138 and MiR-135 directly target focal adhesion kinase, inhibit cell invasion, and increase sensitivity to chemotherapy in cancer cells. Anticancer Agents Med Chem. 2014 Jan;14(1):18-28

Leung CO, Deng W, Ye TM, Ngan HY, Tsao SW, Cheung AN, Pang RT, Yeung WS. miR-135a leads to cervical cancer cell transformation through regulation of $\beta$-catenin via a SIAH1-dependent ubiquitin proteosomal pathway. Carcinogenesis. 2014 Feb 25;

Moritoki Y, Hayashi Y, Mizuno K, Kamisawa $\mathrm{H}$, Nishio $\mathrm{H}$, Kurokawa S, Ugawa S, Kojima Y, Kohri K. Expression profiling of microRNA in cryptorchid testes: miR-135a contributes to the maintenance of spermatogonial stem cells by regulating FoxO1. J Urol. 2014 Apr;191(4):117480

This article should be referenced as such:

Navarro A, Díaz-Beyá M, Monzó M. MIR135A1 (microRNA 135a-1). Atlas Genet Cytogenet Oncol Haematol. 2014; 18(10):718-723. 